\title{
Measurement of domestic hot water consumption in hotel rooms with different basin and shower mixing taps
}

\author{
Harald Taxt Walnum ${ }^{1 *}$, Karolina Stråby ${ }^{1}$ and Aise Lekang Sørensen ${ }^{1}$ \\ ${ }^{1}$ SINTEF Community, Architectural Engineering, 0314 Oslo, Norway
}

\begin{abstract}
Domestic Hot Water (DHW) production constitutes a significant proportion of the energy demand of modern buildings, and as the building envelope is improved the share increases. This article shows results from a measurement campaign on two equal hotel blocks, in the same hotel. There are different basin and shower mixing taps installed in the two hotel blocks, one with original mixers (13-14 1/min) and one with touch-free operated water saving mixers $(5-61 / \mathrm{min})$. The number of guests were registered separately for the two blocks. The results indicate almost a one-to-one relationship between the difference in mixer and total water consumption, resulting in a potential energy saving of 50-60\%. There are no indications that the reduced water flow results in increased duration of each individual shower. However, it is not known if this is due to the use of touch-free operated mixers. Feedback through complains from guests indicate somewhat reduced perceived comfort level from the water saving mixers, and some annoyance caused by the touch-free operation. The results indicate that optimal balance between user comfort and water saving is slightly higher water flow than the applied 5-6 1/min.
\end{abstract}

\section{Introduction}

\subsection{Water and energy consumption for DHW}

In the last decades, there has been an increasing focus on the energy demand in buildings, and the building regulations are moving towards zero energy buildings [1]. The main measures have been on improving the building envelope. As the building space heating demand is reduced, the relative importance of the energy for domestic hot water (DHW) increases. To reduce the energy need for DHW, a better understanding of factors influencing DHW demand is needed [2].

Water saving mixers have been on the marked for a long time, with a large potential for both water and energy savings. Englart and Jedlikowski [3] showed that replacement of traditional taps theoretically could result in more than $50 \%$ water savings, which again would lead to a significant energy reduction. However, the released potential in real installations is challenging to document, due to effects of changed user behaviour (e.g. longer showers). Willis et al. [4] showed a potential for almost $50 \%$ savings in water consumption for showers by switching from high flow mixers to low flow mixers [4]. However, the difference in rated water consumption was significantly higher $(15-25 \mathrm{l} / \mathrm{min}$ vs. 6-7 $1 / \mathrm{min})$. In [5] Mayer et al. evaluated the effect of retrofitting low water flow shower mixers $(9.5 \mathrm{l} / \mathrm{min})$ in single-family homes (water flow of original mixers where not known). They found a $16 \%$ average decrease in water consumption per shower, due to both reduced duration and water flow. The relatively small savings where explained by the fact that some households already had water saving equipment or that they throttled the flow of their existing mixers. Barberán et al. [6] evaluated the effect of retrofitting with flow limiters $(61 / \mathrm{min}$ for basins and $91 / \mathrm{min}$ for showers) in a hotel in Spain. They did not have direct measurements of hot water consumption in rooms, but through statistical analysis they estimated a reduction in hot water consumption of $46 \%$.

In the work presented in this paper, we have been able to directly compare the water and energy consumption for hot water in hotel rooms, with and without water saving mixers.

A measurement campaign has been performed on a hotel, where the hot water consumption has been measured separately in two hotel sections, each with 140 similar hotel rooms: One section with the original shower mixers (13-14 1/min), and one section where the mixers have been changed to touch-free water saving types $(5-6 \mathrm{l} / \mathrm{min})$. The basin mixers where also changed. During the measurement campaign, the number of guests visiting each of the two sections were logged, and general guest feedback was registered. There are several benefits of this measurement setup. By measuring the difference in water consumption simultaneously, one eliminates several external disturbances, such as seasonal and climate related effects. The use of a hotel, compared to e.g. an apartment building, will increase the variation of users with participants from different sociodemographic groups. Since the guests are not aware of the measurement campaign, their behaviour will not be influenced by it either.

\footnotetext{
* Corresponding author: harald.walnum@sintef.no
} 


\subsection{Description of the hotel and equipment}

The hotel is a conference hotel located in the vicinity of the city of Oslo, Norway. It consists of three similar blocks of hotel rooms (A, B and C) and large common areas including restaurant, bar/lounge, and conference areas. The three blocks with hotel rooms are equal in size and have similar layout, with 4 floors, 144 rooms and in total $5000 \mathrm{~m}^{2}$ each. Before the measurement period, all bathrooms in block A were refurbished and new water saving basin and shower mixers were installed. The new shower mixers were equipped with sensors for touch-free operation. The touch-free shower mixers have several functions to reduce consumption:

- The water stops after 20 seconds if no person is detected in the shower,

- The water automatically stops after three minutes and must be restarted.

In block $\mathrm{C}$, the original mixers were still in place during the measurement period.

For each of the three blocks, the hot (HW) and cold (CW) water is supplied from a technical room in the basement. The water is then distributed in the ceiling of the ground floor, and up through Alupex pipes in internal shafts, as shown in Figure 1. All the hot water riser pipes are connected to a joint hot water circulation (HWC) pipe in the top floor ceiling. Hot and cold water is distributed to individual tapping points in each room through a pipe-in-tube system.

\section{Method for measurements}

Two sets of measurements where performed: 1) maximum flow rates for the individual tapping points, and 2) the total hot water consumption in each block during the measurement period. The measurements where performed in the period 05.10.2019 to 28.11.2019. During the period, guests per day where registered for each of the two blocks.

\subsection{Tapping point measurements}

To investigate the difference in flow rate between the installed mixing taps, the individual flow rates were measured with the mixing valve obturator fully open. Temperatures where set to typical showering temperatures (approximately $38^{\circ} \mathrm{C}$ ). Four rooms in each block where selected; two at the ground floor and two at the top floor. In each room both the basin and shower mixers where measured three times. The measurements were performed with the "bucket and stopwatch" method: measuring the time it took to fill a bucket and weighing the content.

\subsection{Hot water consumption measurement}

Flow and temperature measurements where performed on the main supply pipe for each block, according to Figure 1 and Figure $2 . \dot{V}_{H W}$ and $\dot{V}_{H W C}$ are the flow rates in the $\mathrm{HW}$ and $\mathrm{HWC}$ pipes in $\mathrm{m}^{3} / \mathrm{s}$, respectively. The hot water consumption flow rate $\left(\dot{V}_{C H W}\right)$ is calculated according to equation (1).

$$
\dot{V}_{C H W}=\dot{V}_{H W}-\dot{V}_{H W C}
$$

$\mathrm{T}_{\mathrm{HW}}, \mathrm{T}_{\mathrm{HWC}}, \mathrm{T}_{\mathrm{CW}}\left[{ }^{\circ} \mathrm{C}\right]$ are the temperatures in the $\mathrm{HW}$, HWC and CW, respectively.

Flow rates and temperatures were measured with an interval of 1 second, and then averaged to 2 seconds before analysis. An important feature for the measurement equipment was that it had to be nonintrusive to the DHW system. Therefore, clamp-on ultrasonic flow meters were used for flow measurement and Type-T thermocouples where mounted on the pipe wall and insulated on the outside. The flow meters have a specified accuracy of $1.6 \%$ of reading $\pm 0.01 \mathrm{~m} / \mathrm{s}$ [7], and the Type- $\mathrm{T}$ thermocouples have an error specified as maximum of $1.0{ }^{\circ} \mathrm{C}$ or $0.75 \%$ above $0{ }^{\circ} \mathrm{C}$ [8]. Both flow meters and thermocouples where tested and calibrated in in-house laboratories, but field calibration was not possible.

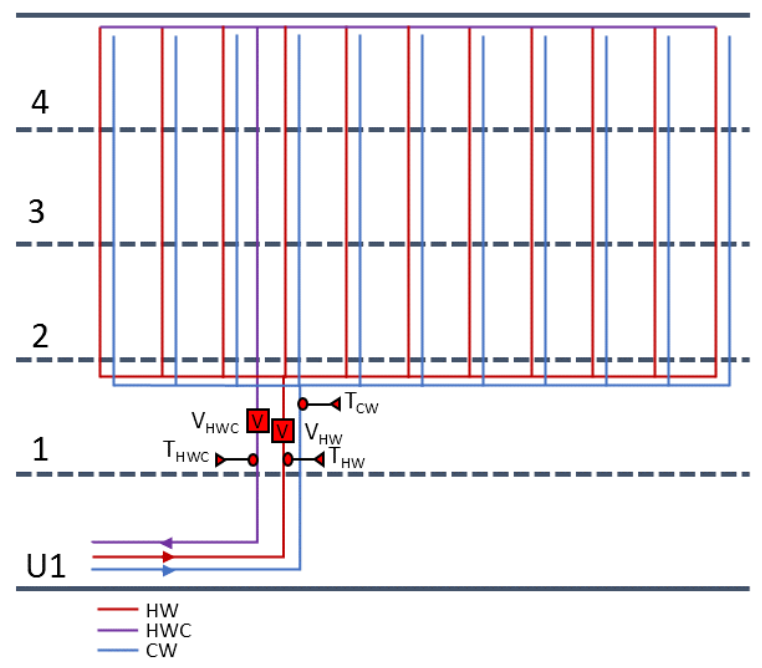

Figure 1. Principle drawing of water distribution system in each of the two blocks, with measurement equipment.

Equation (2) and (3) show the formulas for calculating the thermal energy for consumed hot water $\left(\dot{Q}_{C H W}[\mathrm{~W}]\right)$ and distribution losses $\left(\dot{Q}_{H W C}[\mathrm{~W}]\right)$, respectively, where $\rho\left[\mathrm{kg} / \mathrm{m}^{3}\right]$ is the density of water and $c_{p}[\mathrm{~J} / \mathrm{kgK}]$ is the corresponding heat capacity.

$$
\begin{gathered}
\dot{Q}_{C H W}=\frac{\dot{V}_{C H W}}{\rho} * c_{p} *\left(T_{H W}-T_{C W}\right) \\
\dot{Q}_{H W C}=\frac{\dot{V}_{H W C}}{\rho} * c_{p} *\left(T_{H W}-T_{H W C}\right)
\end{gathered}
$$




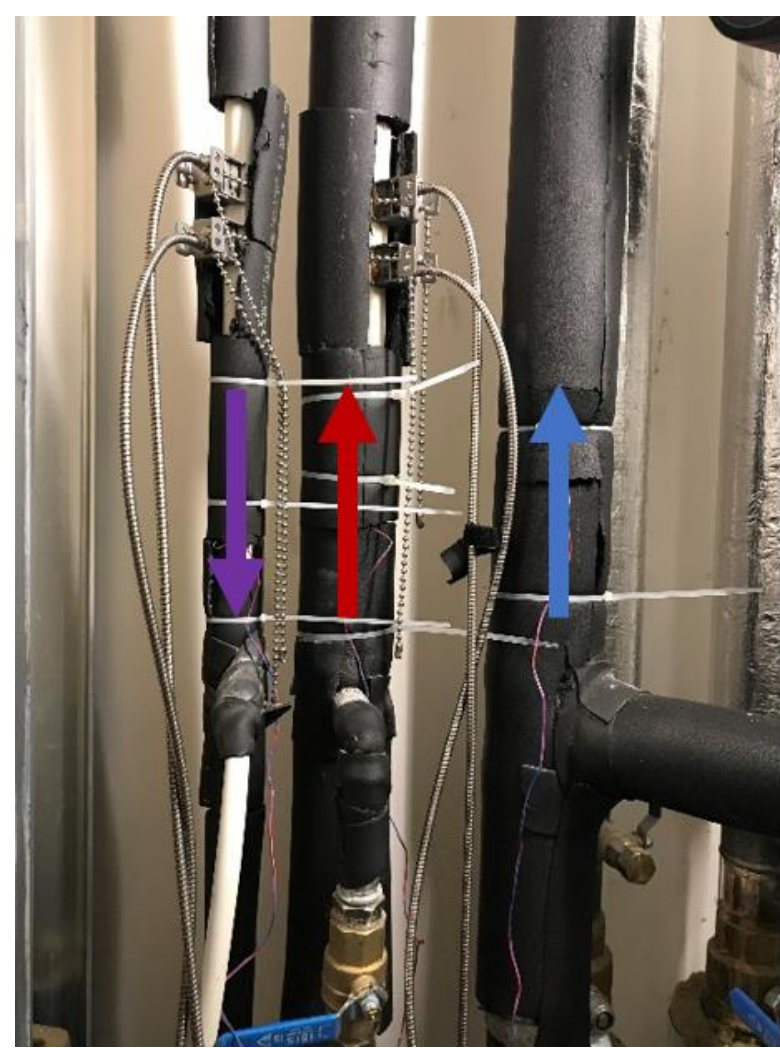

Figure 2: Photo of the installed measurement equipment.

\section{Results}

\subsection{Tapping point measurements}

Figure 3 shows a box plot of the tapping point measurements. The green line in the middle of the box shows the median flow, the box contains the data within the first (Q1) and third (Q3) quartile, while the whiskers represent the least and greatest value excluding outliers. Circles show outliers, which are defined as values extending 1.5 times the interquartile range $(\mathrm{IQR}=\mathrm{Q} 3$ Q1) out from the box. The measurements are divided per block, type of tapping point and floor. In general, one can see that the new mixers in block A have a considerably lower water flow, compared to the original mixers in block $\mathrm{C}$. In average, the water consumption from mixers in block A are about $60 \%$ lower than those in block $\mathrm{C}$. The shower mixers of block $\mathrm{C}$ have an average water flow of about $13 \mathrm{l} / \mathrm{min}$, which can be considered to be normal for shower mixers installed in the 1990s with a minimum required flow rate at $12 \mathrm{l} / \mathrm{min}$ [9]. The average water flow for the shower mixers of block $A$ is below $61 / \mathrm{min}$, which is considered to be in the lower range of the minimum required $4-121 / \mathrm{min}$ for thermostatic shower mixers [10]. One can also see that for block $\mathrm{C}$ there is a higher variance in the measurements, especially between the floors. This can indicate that the older mixers are more sensitive to pressure changes.

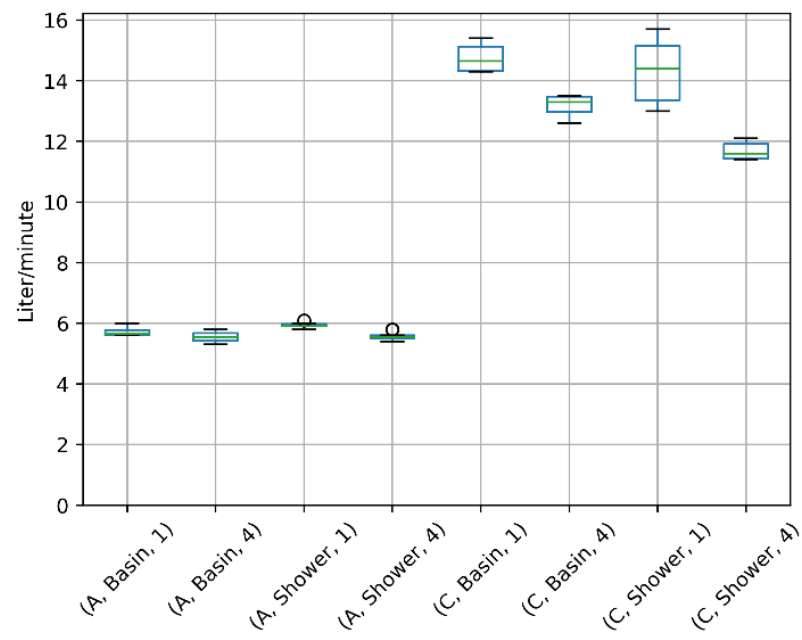

Figure 3: Results from tapping point measurements. X-axis label indicates (block, type of mixer, floor).

\subsection{Guest data}

Figure 4 shows the number of registered guests per day during the measurement period. There are slightly higher number of visitors in block $\mathrm{A}$, but as all data are compared per guest and only consumption related to hotel rooms are measured, the comparison is considered to be valid. This is further confirmed in Figure 7.

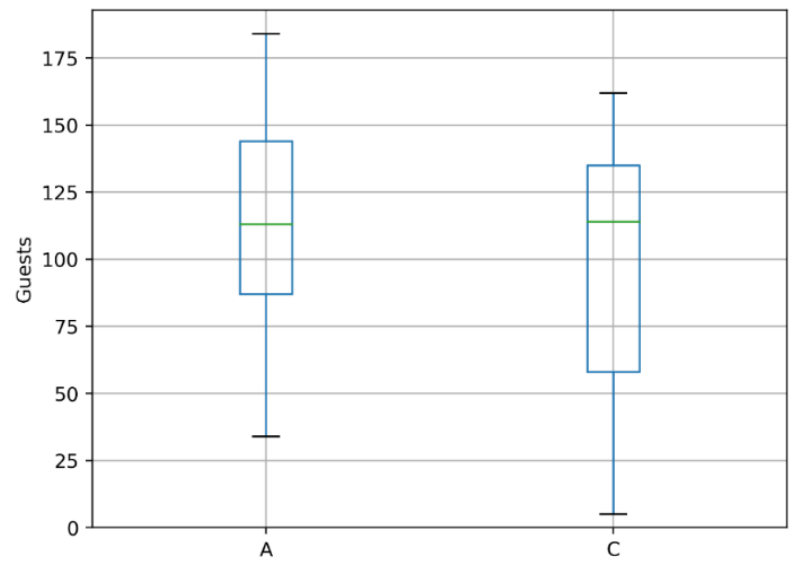

Figure 4: Registered guests per day for each block during the measurement period.

\subsection{Water and energy consumption}

Figure 5 and Figure 6 show the daily water consumption $\left(\dot{V}_{C H W}\right)$ and corresponding energy consumption $\left(\dot{Q}_{C H W}\right)$ per guest, respectively. One can see that the water consumption per guest is about $60 \%$ lower in block $\mathrm{A}$ than in block $\mathrm{C}$, which means an approximately one-to-one relationship between the reduction in water flow per mixer and reduction in the water consumption per guest. This indicates that the lower water flow does not lead to an increase in consumption period. As the energy consumption is a function of the water flow, and the temperatures are relatively constant, the energy consumption follows the same trend. 
Figure 7 shows how the energy consumption per guest varies with number of guests. There is minimal correlation between the two, which shows consumption data per guest is comparable also with different number of guests. However, one can see that the average daily consumption is slightly more disperse with a lower number of guests.

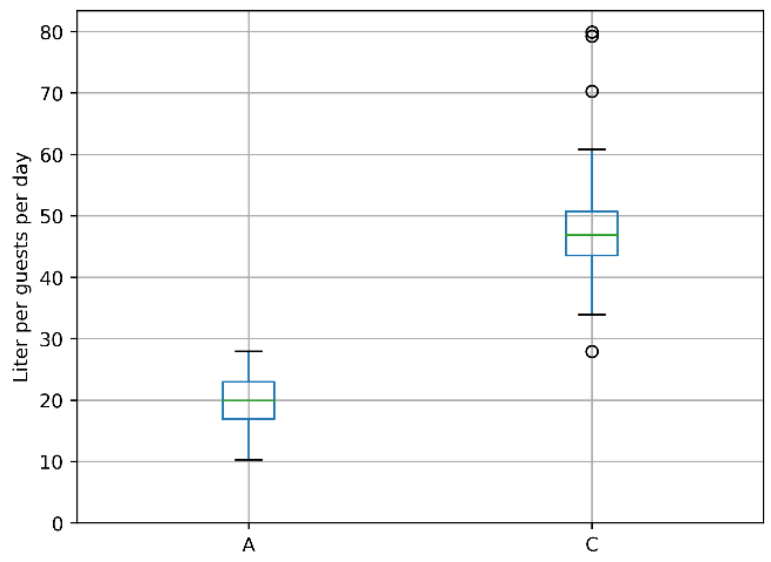

Figure 5: Measured water consumption per guest per day.

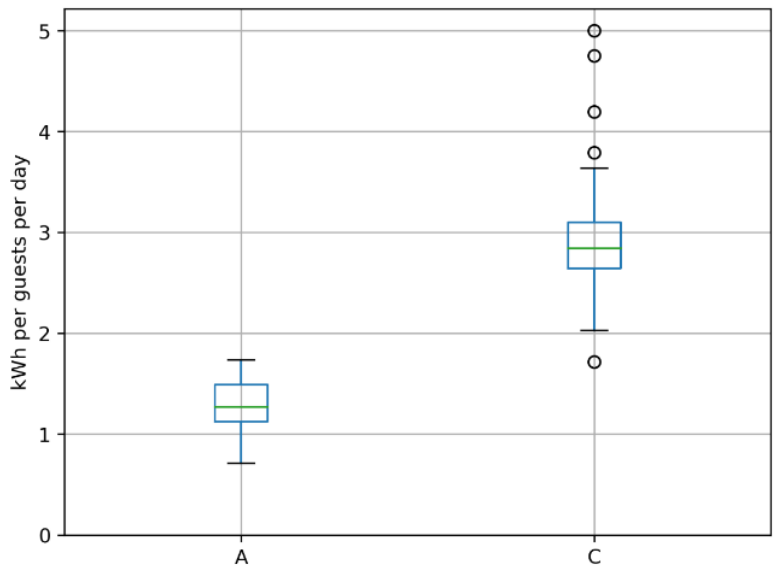

Figure 6: Measured energy consumption per guest per day.

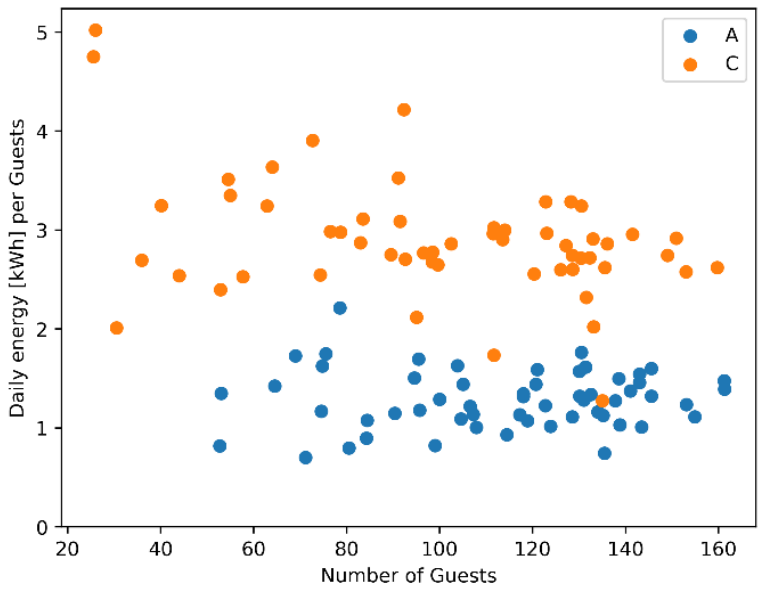

Figure 7: Measured energy consumption per guests vs. number of guests.

Figure 8 compares the daily consumption per guest with measurements from four other Norwegian hotels, measured by the same project [11]. The measurements are not directly comparable as the measurements from the other hotels also includes consumption from other uses, such as restaurants and common areas. However, hotel HO3 is a city hotel without restaurant and other common areas with water consumption. The consumption should therefore be comparable. However, there might be differences in the behaviour of hotel guests at typical city/tourist hotels and conference hotels. In general, the results indicate that block A, with the water saving mixers has lower consumption than the other hotels in the measurement campaign.

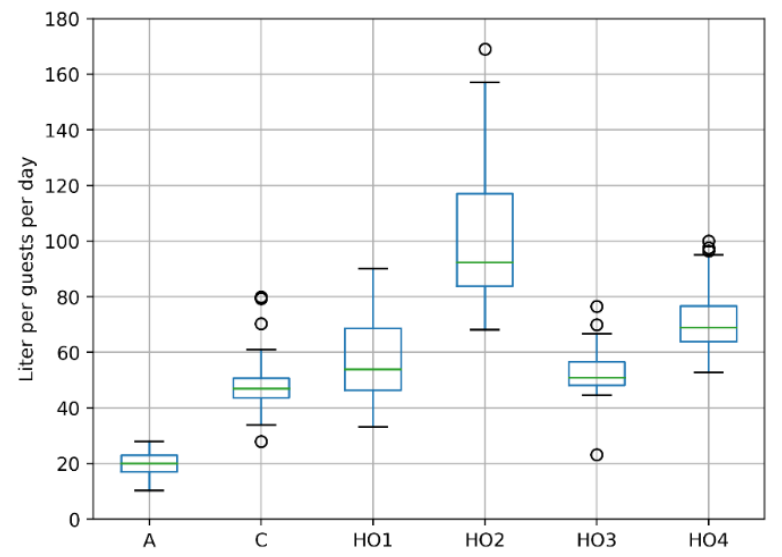

Figure 8: Comparison with measurements from other hotels.

Figure 9 shows the peak water consumption averaged over $10 \mathrm{~s}$ for every day, against number of guests. One can see that the peak consumption per guest has a clear relation to the number of guests. If we assume that each guest can only operate one mixer at a time, we can define the coincidence factor as the measured peak flow divided by the average peak flow of each mixer multiplied by the number of guests. From Figure 9 one can then see that the coincidence factor is reduced with increasing number of guests. For block $A$, the coincidence factor seems to stabilize at around 80-100 guests, while for block $\mathrm{C}$ it reduces further. This could be due to an increased pressure drop in the system when more tapping points are used simultaneously, which in turn reduces the flow from each mixer. This corresponds well with the individual tapping point flow measurements presented in Figure 3, indicating a larger pressure dependency for the mixers in block $\mathrm{C}$.

Based on the average measured flow rate for the mixers, as presented in Figure 3, the number of units (tapping points) in use is estimated during peak consumption periods. An average tapping temperature of $38^{\circ} \mathrm{C}$ is used in the calculation. The results are shown in Figure 10, with number of units in use vs. number of guests. The figure indicates that block $\mathrm{C}$ has a lower number of units in use in periods with a high number of visitors. This rather unexpected result may be explained by an increased pressure drop in block $\mathrm{C}$, as discussed earlier. If so, the estimated flow rate used in the calculation may be higher than the real flow rate, which again would lead to a lower number of units in use than actual. 


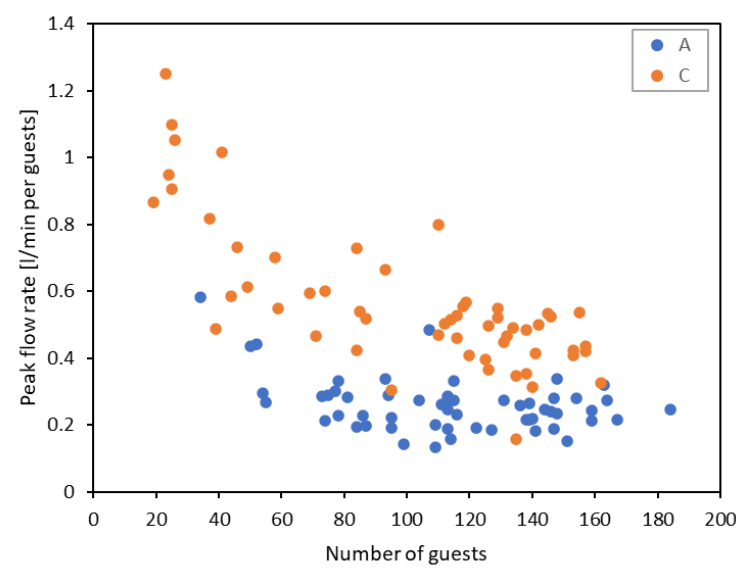

Figure 9: Peak water consumption per guest per day vs. number of guests.

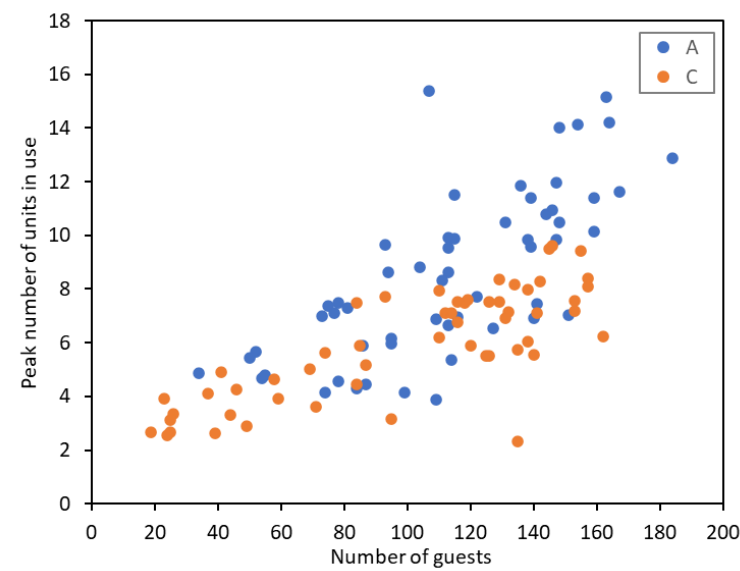

Figure 10: Estimated number of units in use vs. number of guests during peak consumption periods.

Figure 11 and Figure 12 shows boxplots of the hourly energy consumption per guest for block A and block $\mathrm{C}$, respectively. One can see that water is consumed in two main periods, during the morning and in the afternoon. The morning peak is typical for all hotels and is mainly driven by guests showering in the morning. The afternoon peak is typical for conference hotels and probably driven by showering before communal dinners. The afternoon peak has a higher variability than the morning peak, and looking into the consumption on individual days, one can see that these afternoon peaks only occur on some of the days. The negative values in the figures are discussed in 4.1.

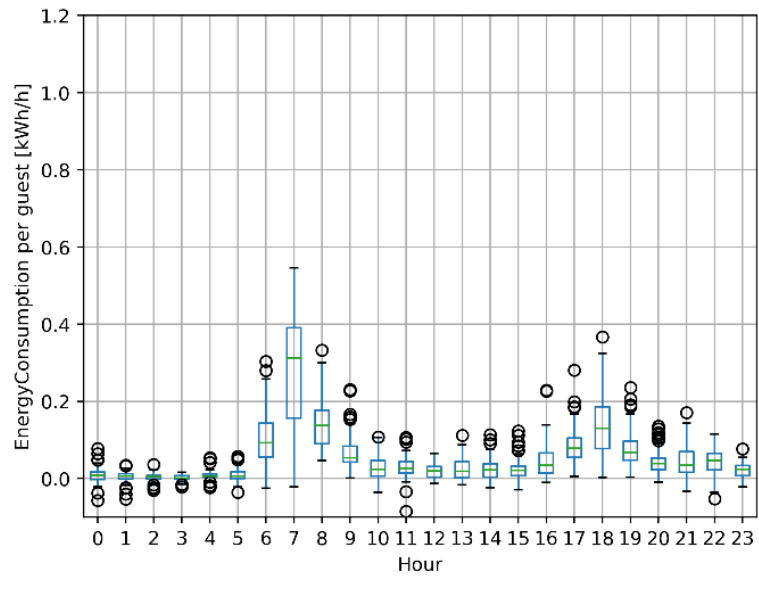

Figure 11: Boxplot of hourly energy consumption for block A.

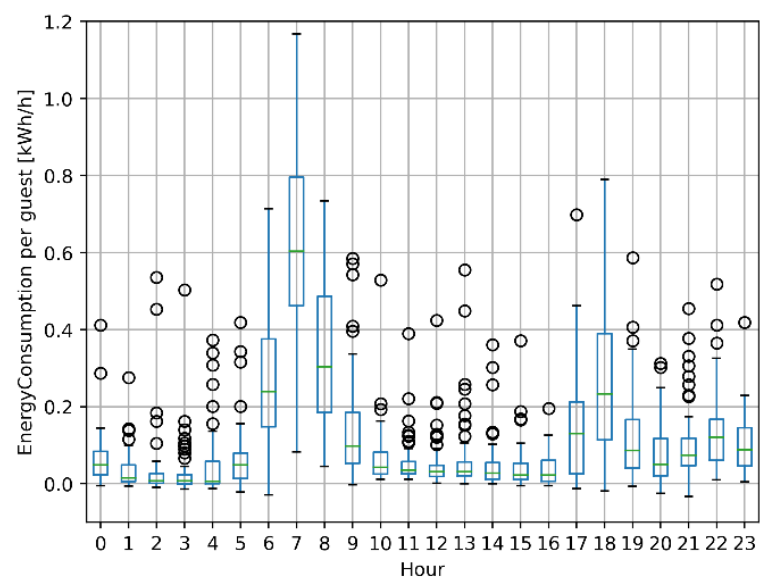

Figure 12: Boxplot of hourly energy consumption for block C.

\section{Discussion}

\subsection{Measurement uncertainties}

There are several sources for uncertainties in the "bucket and stopwatch"- method. Both related to the manual operation of the stopwatch and measuring equipment. However, looking at the variance for the measurements in Figure 3, they are probably small compared to the difference between the type of mixers.

Since it was not possible to calibrate the flow meters at site, there are unknown measurement uncertainties. E.g. incrustation in the pipes can alter the effective pipe diameter. Since the flow meters measure the average velocity and multiplies with the set pipe area to calculate the flow, this can have impact on the accuracy of the measured flow rate. From Figure 11 one can also see that measurements show negative energy consumption. This could partially be due to measurement uncertainties. However, it has been observed in the measurements that at random intervals, the flow in the hot water pipe is reduced for 2-3 minutes, while the flow in the circulation pipe is constant. With about 5 minutes delay, the temperature of the circulation water is reduced a couple of degrees. This could indicate some sort of 
leakage between the cold water and the circulation pipe, which could influence the measurements significantly. Averaging the measurements over 1 minute (to reduce the effect of noise) and removing negative values would increase the energy consumption with about $13 \%$. Doing the same for block $\mathrm{C}$ increases the consumption with only $1 \%$. This could indicate that the water and energy saving potential is somewhat overestimated.

\subsection{Influence of mixers and user operation}

The results show an almost one-to-one relationship between the reduction in flow from the mixers and the water consumed. Even with the measurement uncertainties, it is obvious that the new water saving mixers have a clear effect which is not suppressed by a significant increase in duration of consumption. However, it is not possible to identify how much of the reduced consumption is due to reduced flow rate and how much is due to the touch-free operation. The touchfree operation will stop reckless use of hot water, such as letting the shower on, while doing other tasks. One could also imagine that the need to restart the shower every 3 minutes reduces the average showering period. In addition, using a new type of mixer for the first time can influence the water consumption as it may take longer time to get the desired temperature and flow.

It is also not possible to distinguish water consumption between showers and basin mixers. As hotel guests mainly use hot water for showering and washing hands, it is expected that most of the consumption is from showering.

\subsection{Guest feedback}

The hotel uses a customer feedback system to get response from guests on their satisfaction level of the stay. During a period from August 2019 to February 2020 the hotel had around 54000 overnight stays. In the same period, they received 19 complaints related to the shower experience. 13 of the complaints mentioned low water pressure or flow rate, while 12 mentioned trouble with the touch-free operation. The main concern of the hotel staff is the experience of low water pressure or flow rate. They find it easier to argue for the touch-free operation in an environmental perspective. A comfortable shower is considered an important part of a good hotel experience. Based on this feedback, it might be reasonable to increase the flow rate of the water saving showers somewhat, to increase customer satisfaction. It is still a significant water and energy saving potential compared to using mixers with a flow rate above $12 \mathrm{l} / \mathrm{min}$.

There were no registered complains about the water flow in the basin mixers. As hotel guest normally only use washbasins for washing hands, the need for high flow rates is limited. Even though potential savings for water and energy from basin mixers is limited, water saving equipment is recommended as it does not sacrifice user comfort.

\subsection{Transferability to other building categories}

The relative reduction of water and energy consumption would theoretically be independent of the building category. However, the simultaneous demand of water depends on the type of building and its intended area of use. Studies have shown that the behaviour of different user groups varies, where the DHW demand of hotel guests differ from e.g. residential users and nursing home patients in terms of when, for how long and with what frequency the different tapping points are used [12]-[14].

Compared to households, hotels are different in several ways. E.g. the hotel owner decides type of mixers, not the end user. Studies on the effect of retrofitting water saving mixers normally require voluntary participation. One would expect that people volunteering to these studies in general are more interested in savings related to either resources or economics, and therefore more conscious towards water saving behaviour. Users are also more familiar with the operation of mixers in their own house. Mayer et al. [5] showed that savings when switching to water saving shower mixers where limited since people already throttled the flow of their original mixers. A similar behaviour is not identified in this study.

People also may have an opinion that hotel visits should bring a higher comfort than daily life. Introducing equipment that sacrifices the perceived comfort of the guests is a significant risk for the hotel owner. The aim is therefore to achieve both user comfort and water savings when choosing new mixers.

\section{Conclusions}

A measurement campaign has been performed on two equal hotel blocks, but with different basin and shower mixing taps. The results show a significant reduction in water and energy consumption for the block with water saving mixers installed. The original mixing taps have a measured flow rate of $13-141 / \mathrm{min}$, while the new mixers were measured to $5-6 \mathrm{l} / \mathrm{min}$. The overall water consumption measurements for each hotel section indicate almost a one-to-one relationship between the difference in mixer and total water consumption, resulting in a potential energy saving of $50-60 \%$. There are no indications that the reduced water flow results in increased duration of each individual shower. However, it is not known if this is due to the use of touch-free operated mixers. Feedback from guests indicate somewhat reduced perceived comfort from the new mixers, and some annoyance caused by the touch-free operation. The results indicate that optimal balance between user comfort and water saving is slightly higher water flow than the applied 5-6 1/min.

This article has been written within the research project "Energy for domestic hot water in the Norwegian low emission society". The authors gratefully acknowledge the support from the Research Council of 
Norway (ENERGIX-programme) and the project partners.

\section{References}

[1] L. Belussi et al., "A review of performance of zero energy buildings and energy efficiency solutions," Journal of Building Engineering, vol. 25. Elsevier Ltd, p. 100772, 01-Sep-2019.

[2] E. Fuentes, L. Arce, and J. Salom, "A review of domestic hot water consumption profiles for application in systems and buildings energy performance analysis," Renew. Sustain. Energy Rev., vol. 81, pp. 1530-1547, Jan. 2018.

[3] S. Englart and A. Jedlikowski, "The influence of different water efficiency ratings of taps and mixers on energy and water consumption in buildings," SN Appl. Sci., vol. 1, no. 6, pp. 110, Jun. 2019.

[4] R. M. Willis, R. A. Stewart, D. P. Giurco, M. R. Talebpour, and A. Mousavinejad, "End use water consumption in households: Impact of socio-demographic factors and efficient devices," J. Clean. Prod., vol. 60, pp. 107-115, Dec. 2013.

[5] P. W. Mayer, W. B. DeOreo, E. Towler, and D. M. Lewis, "Residential Indoor Water Conservation Study: Evaluation of High Efficiency Indoor Plumbing Fixture Retrofits in Single-Family Homes in the East Bay Municipal Utility District Service Area," Boulder, Colorado, 2003.

[6] R. Barberán, P. Egea, P. Gracia-de-Rentería, and M. Salvador, "Evaluation of water saving measures in hotels: A Spanish case study," Int. J. Hosp. Manag., vol. 34, no. 1, pp. 181-191, Sep. 2013.

[7] Flexim GmbH, "Technical specification FLUXUS ${ }^{\circledR}$ F601 Portable ultrasonic flow measurement of liquids.” Berlin, Germany, pp. 1-26, 2017.

[8] TE Wire \& Cable, "Calibration Services." [Online]. Available:

https:/tewire.com/calibration-services/. [Accessed: 11-Mar-2019].

[9] CEN, "EN 200:1989 Sanitary tapware General technical specifications for single taps and mixer taps (nominal size 1/2) PN 10 Minimum flow pressure of $0,05 \mathrm{MPa}(0,5$ bar)." 1989.

[10] CEN, "NS-EN 1111:2017 Sanitary tapware Thermostatic mixing valves (PN 10) - General technical specification." 2017.

[11] SINTEF, "Energy for domestic hot water in the Norwegian low emission society," 2017.

[Online]. Available:

https:/www.sintef.no/projectweb/varmtvann/e nglish/\#/. [Accessed: 14-Dec-2020].
[12] E. J. M. Blokker, J. H. G. Vreeburg, and J. C. van Dijk, "Simulating Residential Water Demand with a Stochastic End-Use Model," J. Water Resour. Plan. Manag., vol. 136, no. 1, pp. 19-26, Jan. 2010.

[13] D. Loureiro, S. T. Coelho, P. Machado, A. Santos, H. Alegre, and D. Covas, "Profiling Residential Water Consumption," in Water Distribution Systems Analysis Symposium 2006, 2008, pp. 1-18.

[14] H. Taxt Walnum, Å. L. Sørensen, B. Ludvigsen, and D. Ivanko, "Energy consumption for domestic hot water use in Norwegian hotels and nursing homes," in IOP Conference Series: Materials Science and Engineering, 2019, vol. 609, no. 5, p. 052020. 